Gillman MW, Gluckman PD, Rosenfeld RG (eds): Recent Advances in Growth Research: Nutritional, Molecular and Endocrine Perspectives.

Nestlé Nutr Inst Workshop Ser, vol 71, pp 11-27, (DOI: 10.1159/000342533)

Nestec Ltd., Vevey/S. Karger AG., Basel, ๔ 2013

\title{
Early Influences of Nutrition on Postnatal Growth
}

\author{
Berthold Koletzko ${ }^{\mathrm{a}}$. Jeanette Beyer ${ }^{\mathrm{a}}$ Brigitte Brands ${ }^{\mathrm{a}}$. \\ Hans Demmelmair ${ }^{\mathrm{a}}$ Veit Grote ${ }^{\mathrm{a}}$ Gudrun Haile $^{\mathrm{a}}$. \\ Dariusz Gruszfeld ${ }^{b}$ Peter Rzehak $k^{\mathrm{a}}$ Piotr Socha ${ }^{\mathrm{b}}$. \\ Martina Weber ${ }^{\mathrm{a}}$ for The European Childhood Obesity \\ Trial Study Group
}

${ }^{a}$ Dr. von Hauner Children's Hospital, University of Munich Medical Centre, Munich,

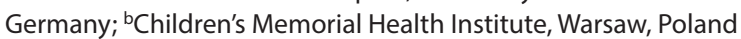

\begin{abstract}
Health and nutrition modulate postnatal growth. The availability of amino acids and energy, and insulin and insulin-like growth factor-I (IGF-I) regulates early growth through the mTOR pathway. Amino acids and glucose also stimulate the secretion of IGF-I and insulin. Postnatal growth induces lasting, programming effects on later body size and adiposity in animals and in human observational studies. Rapid weight gain in infancy and the first 2 years was shown to predict increased obesity risk in childhood and adulthood. Breastfeeding leads to lesser high weight gain in infancy and reduces obesity risk in later life by about $20 \%$, presumably partly due to the lower protein supply with human milk than conventional infant formula. In a large randomized clinical trial, we tested the hypothesis that reduced infant formula protein contents lower insulin-releasing amino acid concentrations and thereby decrease circulating insulin and IGF-I levels, resulting in lesser early weight gain and reduced later obesity risk (the 'Early Protein Hypothesis'). The results demonstrate that lowered protein in infant formula induces similar - but not equal - metabolic and endocrine responses and normalizes weight and BMI relative to breastfed controls at the age of 2 years. The results available should lead to enhanced efforts to actively promote, protect and support breastfeeding. For infants that are not breastfed or not fully breastfed, the use of infant formulas with lower protein contents but high protein quality appears preferable. Cows' milk as a drink provides high protein intake and should be avoided in infancy.
\end{abstract}


Growth and development are key characteristics of childhood and sensitive markers of health status and adequate nutrition. Pediatricians regularly monitor the growth patterns of children as part of standard routine care, usually by plotting repeated growth measures over time on percentile reference curves to derive longitudinal growth patterns. Traditionally, this approach served primarily to early detect growth faltering as a marker of the presence of infectious and other diseases, or of inadequate nutrition, which show particularly rapid adverse effects on growth in infancy and early childhood [1]. More recently, however, the impact of excessive growth on child health has been receiving increasing attention [2-4].

In 1989, Karlberg [5] described the Infancy-Childhood-Puberty Growth Model (ICP model) of growth, and proposed the key drivers of growth to be age dependent. Karlberg concluded that pubertal growth is primarily driven by sex hormones, whereas prepubertal growth is regulated primarily by human growth hormone (hGH) acting through the release of insulin-like growth factor-I (IGFI). In addition, dietary factors and especially the intakes of energy and protein are very important regulators of serum IGF-I concentrations and its biological activity, especially during the first months of infancy [6]. Amino acids were also reported to be more potent stimulators of IGF-I release than glucose [7]. For example, studies in 4-week-old rats showed that feeding a diet with 15 instead of $5 \%$ protein for only one week increased serum IGF-I more than 4 -fold [8]. With increasing age of the child, there appears to be a gradual transition to a more important role of hGH in the regulation of IGF-I, along with increasing concentrations of growth hormone-binding proteins that are considered to reflect hGH receptor numbers $[9,10]$. Nutrition also markedly influences insulin secretion which has key regulatory roles for anabolic pathways as well as tissue and lipid deposition during early growth $[11,12]$. Glucose concentration is a key driver of insulin secretion, but the glucose-induced insulin secretion was shown to be markedly attenuated by a low protein supply [13]. Amino acids such as leucine also enhance insulin secretion via both acute effects, such as activated glutamate dehydrogenase activity, and chronic effects such as gene transcription and regulation of $\beta$-cell metabolism [14].

One pathway though which nutrients as well as the growth factors insulin and IGF-I can effectively modulate growth and metabolism is the mammalian target of rapamycin (mTOR), a highly conserved Ser/Thr kinase present in two structurally and functionally distinct complexes [15]. The mTORcomplex 1 (mTORC1) contains mTOR, mLST8, and raptor, whereas mTORC2 is composed of mTOR, mLST8, rictor, mSIN1, and PRR5. The growth factors insulin and IGF-I stimulate mTORC2 via an unknown pathway, and mTORC1 via PI3K and Akt inducing the mTORC1 activator Rheb [15]. Amino acids enhance ATP loading of RAG proteins and RAG-GTPases, which interact with Rheb and activate mTORC1 [15]. Of importance, full activation of mTORC1 is only achieved through the synergistic action of both growth factors and amino acids, while a low energy supply downregulates mTORC1 [15]. Thus, this pathway represents an elaborate sensor 
system by which nutritional supply regulates metabolism and growth. The enormous power of this system is demonstrated, for example, in mice with knockout of raptor in adipose tissue, which leads to disruption of mTORC1. These mice are lean and resistant to diet-induced obesity, and they have improved metabolic characteristics such as better glucose tolerance and insulin sensitivity, as well as resistance to diet-induced hypercholesterolemia [16]. These observations lead us to the conclusion that regulation of $\mathrm{mTORC1}$ signaling by amino acids controls whole-body energy metabolism, bodyweight and body composition. Therefore, the current knowledge on the physiological mechanisms regulating metabolism, growth and related outcomes relevant for health indicate the large potential that improved nutritional practice during early life can have on long-term disease prevention and well-being, a concept widely known as early nutritional programming of life-long health [17-23]. Results of a recent randomized intervention trial in human infants demonstrate the powerful effects of modifying protein supply on metabolic and endocrine response as well as growth [24].

\section{Postnatal Diet, Growth Patterns, and the Later Risk of Obesity and Related Non-Communicable Diseases}

In early systematic studies performed already in the 1960s, McCance and Widdowson [25] demonstrated programming effects of food restriction for 3 weeks in the early life of animals which led to permanent reduction of bodyweight up to adulthood, whereas no such permanent effects were induced when the same degree of food restriction was induced at a later age. In humans, such postnatal programming effects on later body size have also been reported [26]. Both high birthweight and high weight gain in the first 2 years of life are associated with increased risk for later obesity, as reviewed in Koletzko et al. [27]. For example, we found early growth patterns predictive of overweight risk at school age in a study on 4,235 German children aged 5-6 years that were participating in the obligatory school entry health examination in Bavaria, Germany. Data on early gains of weight, length, body mass index (BMI) and Ponderal Index were derived from the measurements taken during the preventive health care checks offered to all children at birth, 6, 12 and 24 months [28]. Overweight at school entry was assessed according to gender- and age-specific BMI cutoff points. Among all the anthropometric measures and time intervals assessed, weight gain from birth to age 2 years was the best predictor of overweight at school age. Similarly, many studies in other populations also found early rapid weight gain associated with an increased risk of later obesity. Several recent systematic reviews on observational studies concluded that rapid weight gain in infancy and the first 2 years of life is a significant risk indicator for later adiposity [29-32].

Figure 1 shows the increased odds of later obesity during different age categories from childhood to adulthood predicted by early rapid weight gain, defined as 


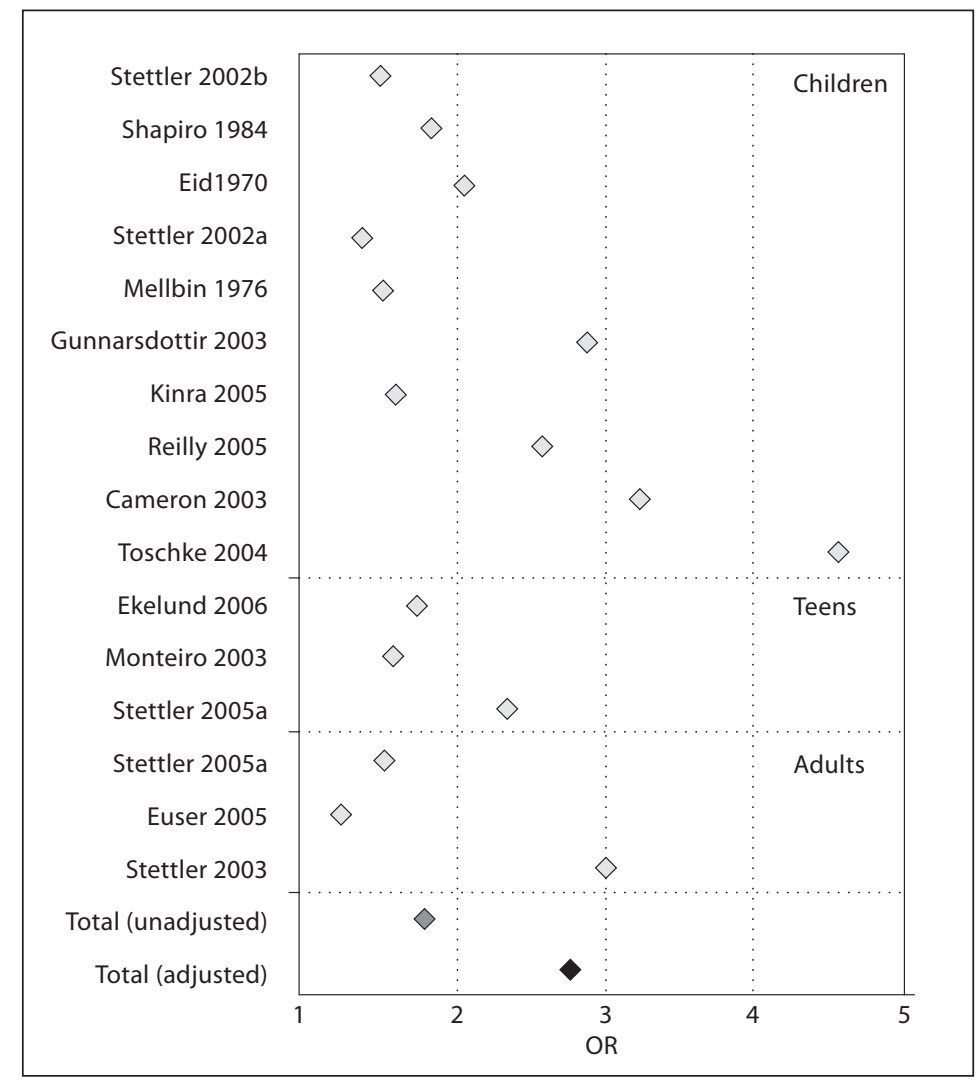

Fig. 1. Rapid weight gain in infancy or the first 2 years of life, defined as an increase in weight-for-age SDS $>0.67 \mathrm{SD}$, is associated with increased odds of obesity in children, teenagers and adults. Redrawn from Adair [33] based on data in Baird et al. [29].

an increase in weight-for-age standard deviation score (SDS) $>0.67$ SD $[29,33]$. In addition to an increased obesity risk, high early weight gain in the first 1-2 years of life is associated with a variety of other later adverse health outcomes [34-36] such as increased risk of high blood pressure [37], increased body fat deposition [28, 38,39 ], less favorable lipoprotein profiles [40], diabetes [41] and asthma [42-44].

\section{Protective Effects of Breastfeeding on Obesity Risk in Later Life}

Populations of breastfed infants grow somewhat differently from formula-fed populations. In poor populations challenged by high rates of infection and diarrhea, the protective effects of breastfeeding against infectious gastroenteritis reduces growth faltering and can thus lead to higher mean weight gains of breastfed babies than of infants not receiving human milk [45-47]. With 


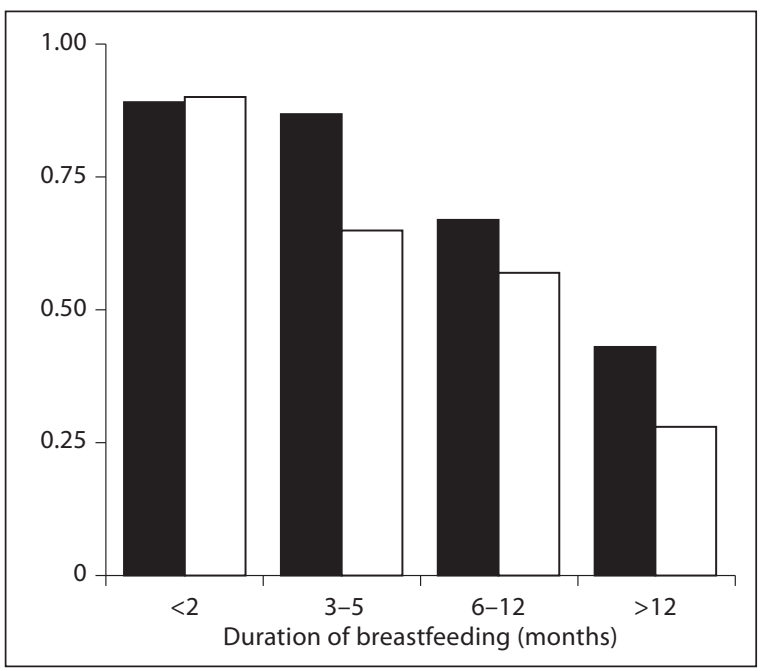

Fig. 2. In a cross-sectional study in $>9,000$ Bavarian children at school entry, longer duration of breastfeeding after birth (months) was associated with increasingly reduced odds of overweight (black) and obesity (white). Drawn from data of von Kries et al. [51].

adequate hygienic conditions, however, infants fed conventional infant formula achieve a greater gain of bodyweight and weight-for-length during infancy and early childhood than breastfed infants [48, 49]. In a systematic review of 19 studies in affluent populations, the cumulative difference in bodyweight was as large as $400 \mathrm{~g}$ at one year of age in infants breastfed for 9 months, and even 600-650 g in infants breastfed for 12 months [50].

Given these marked differences in early growth pattern, we explored the potential effects of these early growth differences on later body size. We studied the relation of breastfeeding with later overweight and obesity risk in a cross-sectional survey in Bavaria, Germany [51]. Data on height and weight were obtained for 9,357 children participating in the obligatory school health examination. Previously breastfed children showed a lower prevalence of both overweight (9.2 vs. $12.6 \%)$ and obesity (2.8 vs. $4.5 \%)$ than formula-fed ones. Differences in social class or lifestyle did not explain the protective effect of breastfeeding. Children who had ever been breastfed showed a significantly reduced adjusted odds ratio (OR) for both overweight (OR 0.79, 95\% CI: 0.68 0.93 ) and obesity (OR $0.75,95 \%$ CI: $0.57-0.98$ ) as compared to those who were never breastfed. The adjusted ORs showed a significant inverse dose-response relationship between duration of breastfeeding and both overweight and obesity, which is compatible with a causal effect of breastfeeding or breast milk components on obesity reduction (fig. 2).

Many other investigators also explored the relationship between breastfeeding and later obesity in different cohort studies. These have been evaluated in 
several systematic reviews and meta-analyses $[45,46]$. We performed a metaanalysis of published epidemiological studies (cohort, case-control or crosssectional studies) that included only studies adjusting for at least three relevant confounding factors (birthweight, parental overweight, parental smoking, dietary factors, physical activity and socioeconomic status/parental education) and assessed obesity at an age between 5 and 18 years [52]. Included were 9 studies with more than 69,000 children. The result of the meta-analysis showed breastfeeding associated with a significant reduction of the risk of obesity in childhood in the fixed model (adjusted OR 0.78, 95\% CI: 0.71-0.85). A dose-dependent effect of breastfeeding duration on the prevalence of obesity was reported in 4 of the 9 studies. Funnel plot regression gave no indication of publication bias. Very similar results were published one year later by Harder et al. [53] in a meta-analysis with different inclusion criteria and a much larger number of studies evaluated. They found breastfeeding associated with reduced pooled adjusted OR for later obesity of 0.75 (95\% CI: $0.68-0.82)$ and concluded that each additional month of breastfeeding resulted in $4 \%$ lower obesity prevalence at later ages. In a further meta-analysis, Owen et al. [54] confirmed a protective effect of breastfeeding in a meta-analysis based on an even larger number of studies that met their inclusion criteria but reported a smaller effect size (OR 0.87). In this analysis, $75 \%$ of the effect weight was contributed by a single large study from the US Women, Infants and Children program on low-income women and children [17]. This study included a specific US population with a high degree of mixed feeding that might have led to results which are not representative of other breastfed populations. A more recent cluster randomized study did cast doubt on the protective effect of breastfeeding on obesity risk. The trial had been performed in hospitals in Belarus that were either assigned to enhanced breastfeeding promotion, or to no active intervention [55]. Whereas the intervention achieved a significantly longer duration of breastfeeding, there was no effect on obesity prevalence at the age of 6.5 years. However, it is important to note that this trial did not have sufficient statistical power to answer the question of a protective effect of breastfeeding relative to formula feeding, because rates of breastfeeding were relatively similar in the intervention and control groups, and the prevalence of obesity was low in this population [56]. Of interest, Beyerlein and von Kries [56] and Beyerlein et al. [57] found evidence that breastfeeding reduces particularly the proportion of subjects with a high BMI at later ages, while having little effect on the mean BMI.

We conclude that the totality of the evidence shows breastfeeding associated with a moderate but consistent protective effect against later obesity. Clearly, these findings should encourage the promotion, protection and support of breastfeeding, and of ethical approaches to the marketing of breast milk substitutes such as infant formulas and follow-on formulas, which do not undermine breastfeeding $[58,59]$. 


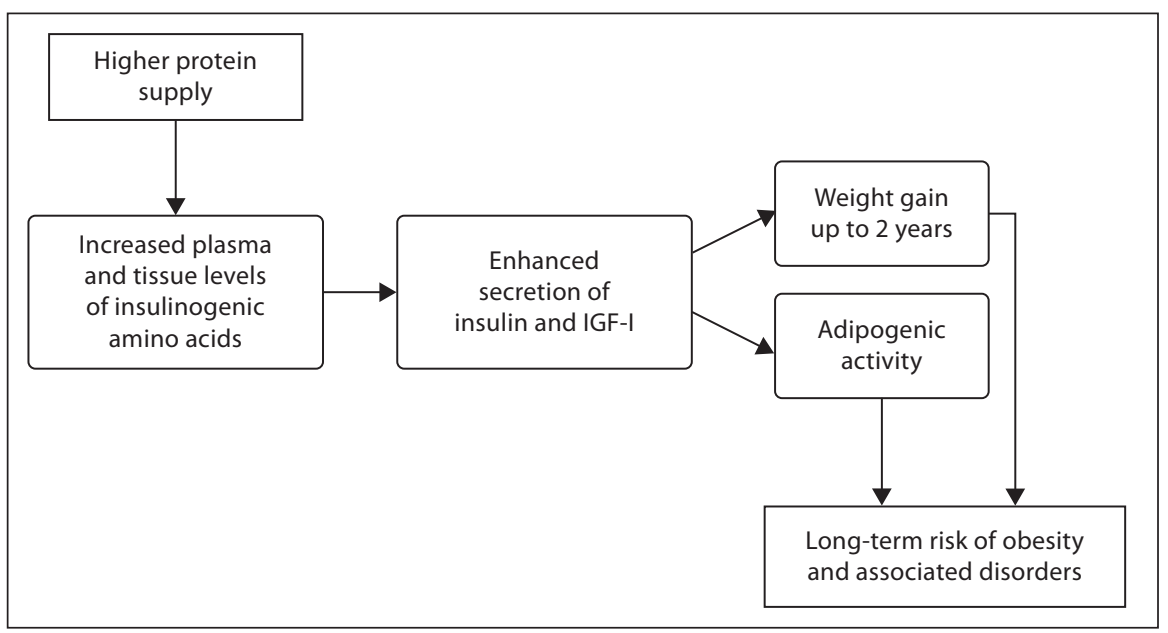

Fig. 3. The Early Protein Hypothesis suggests that a dietary protein supply to infants in excess of their metabolic requirements will lead to increased plasma and tissue concentrations of insulin-releasing amino acids and an enhanced secretion of insulin and IGF-I, which in turn will enhance early weight gain, adipogenic activity and long-term obesity risk. Redrawn after Koletzko et al. [23].

\section{Mechanisms of Protective Effects of Breastfeeding: The 'Early Protein Hypothesis'}

Understanding the underlying mechanisms as to how breastfeeding protects against later obesity could strengthen the conclusions on protective effects of breastfeeding, and it might help to extend protective effects to infants that are not breastfed for longer time periods by improving practices of feeding formula or complementary foods. Very many factors differ between breastfeeding and bottle feeding; therefore, numerous different hypotheses can be raised here [17].

We have previously proposed that the greater weight gain in formula-fed infants, relative to breastfed infants, is at least partly caused by the different intakes of metabolizable protein [50]. We explored the hypothesis that the usually $55-80 \%$ higher protein supply to formula-fed babies, as compared to breastfed infants $[60,61]$, could enhance both early weight gain and later obesity risk (the 'Early Protein Hypothesis') [62]. As described above, amino acids stimulate the secretion of insulin and IGF-I and positively activate mTORC1; thus, a high protein intake in excess of metabolic requirements may increase the concentrations of insulin and IGF-I in the circulation (fig. 3). Epidemiological studies actually found high protein intakes in infancy and the 2 nd year, but not of energy, fat or carbohydrates, predictive of an early occurrence of the adiposity rebound and a high BMI in childhood [63-67]. 
We tested the Early Protein Hypothesis in a randomized clinical trial, the European Childhood Obesity Project [24] performed as part of a European Commission-funded research collaboration [68]. This multicentric RCT was set up in study centers in five European countries (Belgium, Germany, Italy, Poland, Spain). Eligible for study participation were apparently healthy, term infants born from uncomplicated, singleton pregnancies. Formula-fed infants received exclusively one of the two randomized formulas at a mean age of 2 weeks after birth and no later than at the end of the 8 th week of life. Breastfed children had to be exclusively breastfed for the first 3 months. Infant formulas were replaced by follow-on formulas from the 5 th month of age onwards.

The lower protein (LP) and higher protein (HP) infant and follow-on formulas had an identical energy density achieved by adaptation of the fat content, whereas the protein contents were $1.8 \mathrm{~g}$ protein/100 kcal versus $2.9 \mathrm{~g}$ protein/100 $\mathrm{kcal}$ in the infant formulas and $2.2 \mathrm{~g}$ protein $/ 100 \mathrm{kcal}$ versus $4.4 \mathrm{~g}$ protein $/ \mathrm{kcal}$ in the follow-on formulas (table 1). The relative contents of amino acids did not differ between all four formulas, e.g. branched-chained amino acids made up $23 \%$ of the protein content in all four formulas (table 1).

A reference group of 619 breastfed infants was recruited, of whom 298 children could be followed until the 24 months visit. Complete anthropometric follow-up data at 24 months were available for $313 \mathrm{LP}$ infants (follow-up rate = $58 \%)$ and $323 \mathrm{HP}$ infants (59\%). The median age at the baseline visit was 16 days (interquartile range, IQR: 2-29 days). The protein intake was significantly different between the two formula groups at all time points up to 12 months of age but not thereafter. The difference ranged between $5.5 \mathrm{~g}$ per day $(95 \%$ CI: 5.1-5.9) in the first month to $8.5 \mathrm{~g}(7.8-9.3)$ at 6 months. Energy intake in the LP and HP formula groups was identical at 3, 12, and 24 months, but was slightly higher (24 kcal, 95\% CI: 6-43) at 6 months of age in the LP formula group.

Differences in weight and weight-for-length between the formula groups emerged at 6 months of age and remained relatively stable thereafter with a decreasing tendency towards the end of the study. At 24 months of age, length was not different between the intervention groups. The mean weight attained at 24 months was 12.42 and $12.60 \mathrm{~kg}$ for the LP and HP groups, respectively. HP led to a significantly higher BMI than LP during the intervention period from 6 months onwards as well as after the end of the intervention (fig. 4). Of interest, the BMI in the LP group was identical to the breastfed group at 2 years of age. The effect of the intervention was not different among the countries for any of the analyzed anthropometric measures. In addition to total body growth, also a significant effect on kidney growth was found [69]. We estimated the potential impact of the reduced protein intake in infancy on obesity in adolescence based on the observed effects of change in weight-forlength gain during the first 2 years of life on later obesity in large prospective cohort studies, and we calculated an expected reduction of obesity prevalence 
Table 1. Macronutrient and amino acid content of study formulas with LP and HP used in the European Childhood Obesity Trial

\begin{tabular}{|c|c|c|c|c|}
\hline & \multicolumn{2}{|c|}{ Infant formula } & \multicolumn{2}{|c|}{ Follow-on formula } \\
\hline & LP & $\mathrm{HP}$ & LP & HP \\
\hline Energy, g/100 ml & 69.9 & 69.8 & 72.7 & 72.5 \\
\hline Proteins, g/100 ml & 1.25 & 2.05 & 1.6 & 3.2 \\
\hline Percent energy & 7.1 & 11.7 & 8.8 & 17.6 \\
\hline Lipids, g/100 ml & 3.9 & 3.5 & 4.0 & 3.3 \\
\hline Carbohydrates, g/100 ml & 7.5 & 7.5 & 7.6 & 7.6 \\
\hline \multicolumn{5}{|l|}{ Amino acids } \\
\hline Glutamic acid, mg/100 ml & 286 & 473 & 369 & 738 \\
\hline Proline, mg/100 ml & 135 & 223 & 174 & 348 \\
\hline Leucine, mg/100 ml & 119 & 197 & 154 & 308 \\
\hline Lysine, mg/100 ml & 94 & 155 & 121 & 243 \\
\hline Asparagine, mg/100 ml & 89 & 147 & 115 & 230 \\
\hline Valine, mg/100 ml & 84 & 139 & 108 & 216 \\
\hline Isoleucine, mg/100 ml & 77 & 128 & 100 & 200 \\
\hline Serine, mg/100ml & 71 & 118 & 92 & 184 \\
\hline Tyrosine, mg/100 ml & 62 & 103 & 80 & 161 \\
\hline Phenylalanine, mg/100 ml & 58 & 97 & 75 & 151 \\
\hline Threonine, mg/100 ml & 56 & 92 & 72 & 144 \\
\hline Arginine, mg/100 ml & 50 & 74 & 57 & 115 \\
\hline Alanine, mg/100 ml & 42 & 69 & 54 & 108 \\
\hline Histidine, mg/100 ml & 32 & 53 & 41 & 82 \\
\hline Glycine, mg/100 ml & 24 & 40 & 31 & 62 \\
\hline Tryptophane, mg/100 ml & 22 & 29 & 23 & 46 \\
\hline Cystine + methionine, $\mathrm{mg} / 100 \mathrm{ml}$ & 40 & 66 & 52 & 103 \\
\hline
\end{tabular}

Adapted from Koletzko et al. [24] and Socha et al. [71].

at $14-16$ years by $13 \%$ [24]. The actual effects of the intervention after the early toddler age are currently being explored in a longer term follow-up study.

\section{Biochemical and Endocrine Markers}

To explore our underlying hypothesis that the effect of dietary protein on growth and obesity risk is mediated by amino acid concentrations, insulin and IGF-I, we performed respective analyses in venous blood and in urine samples that were obtained from participating infants at the age of 6 months and were analyzed in one central laboratory [70]. 


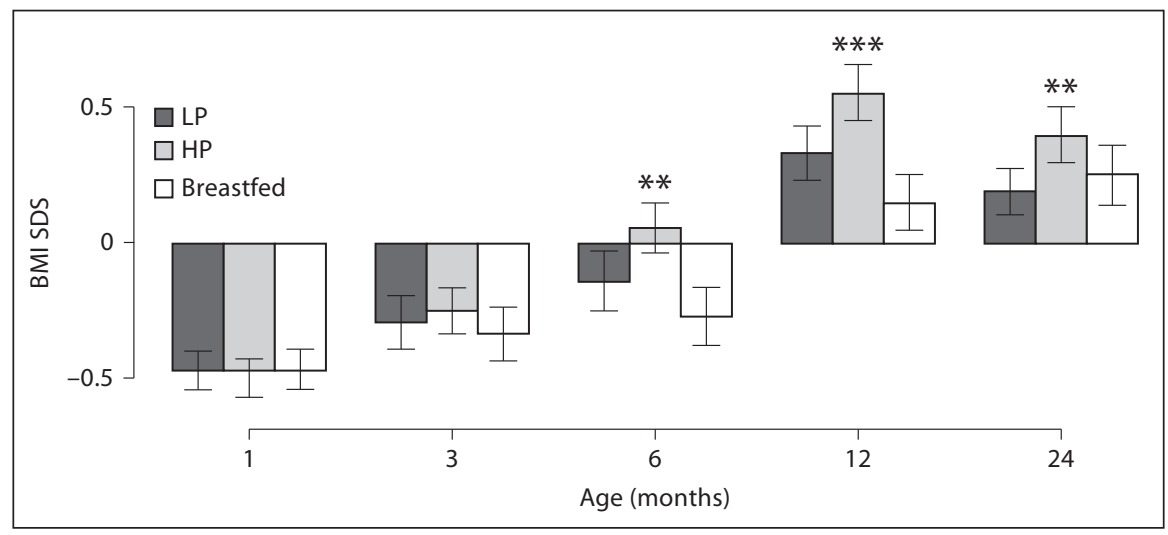

Fig. 4. BMI SDS from birth to age 2 years in subjects participating in the European Childhood Obesity Project fed breast milk, or randomized to receive for the first year of life formulas with LP or HP contents. Formula-fed infants in the HP group showed higher $B M I$ values than breastfed infants in infancy and at 2 years of age. The group randomized to LP had significantly lower BMI levels than the HP group, and LP normalized BMI levels at age 2 years as compared to breastfed subjects. Drawn from data of Koletzko et al. [24].

Median total amino acid serum concentrations were slightly higher in the HP group $(3,041 \mu \mathrm{mol} / \mathrm{l}$, IQR $2,679-3,394)$ than in the LP group $(2,841 \mu \mathrm{mol} / \mathrm{l}$, IQR 2,523-3,186, $\mathrm{p}<0.001)$. Particularly large group differences were found for the branched-chain amino acids valine $(+42 \%$ in HP), leucine $(+37 \%)$ and isoleucine $(+32 \%$; table 2$)$. The concentrations of all other essential amino acids were at least $10 \%$ higher in HP than in LP. In contrast, non-essential amino acids were either not different or even lower in the HP group, with the exception of tyrosine and asparagine which were both significantly higher. Interestingly enough, the total non-essential amino acid concentrations were not higher but significantly lower in the HP group ( $p=0.001)$ [70].

Serum urea concentrations were significantly higher in infants fed HP than in those fed LP formulas (table 3). In the HP group, the serum concentrations of total IGF-I and free IGF-I were about $40 \%$ higher than in the LP group (table 3 ), while IGF-BP2 concentrations were about 30\% lower. The HP group also showed a higher urinary C-peptide concentration and C-peptide/creatinine ratio, indicating enhanced insulin secretion, as well as a significantly lower serum glucose concentration (table 3 ).

Both formula groups showed differences to the breastfeeding group. Generally, parameters of the IGF axis, C-peptide and amino acids were more similar between the LP group and the breastfed group. Total IGF-I, free IGFI, and IGF-BP3 levels were all significantly lower - up to almost $60 \%$ - in the breastfed than in the formula groups (table 3) [70]. Serum glucose, urinary $\mathrm{C}$-peptide and the C-peptide/creatinine ratio all differed significantly between 
Table 2. Serum amino acid (AA) concentrations in infants aged 6 months fed HP and LP formula, and in breastfed infants (BF)

\begin{tabular}{|c|c|c|c|c|}
\hline & LP & $\mathrm{HP}$ & $\begin{array}{l}\text { p value } \\
\text { (HP vs. LP) }\end{array}$ & $\mathrm{BF}$ \\
\hline \multicolumn{5}{|c|}{ Essential amino acids } \\
\hline ILE, $\mu \mathrm{mol} / / \mathrm{I}$ & $64(50,80)^{a}$ & $85(62,114)^{f}$ & $<0.001$ & $58(46,74)$ \\
\hline LEU, $\mu \mathrm{mol} / \mathrm{I}$ & $120(98,143)^{b}$ & $165(124,212)^{f}$ & $<0.001$ & $106(90,133)$ \\
\hline LYS, $\mu \mathrm{mol} / \mathrm{l}$ & $166(134,197)^{c}$ & $197(156,248)^{f}$ & $<0.001$ & $145(121,184)$ \\
\hline $\mathrm{MET}, \mu \mathrm{mol} / \mathrm{l}$ & $31(26,39)^{c}$ & $35(26,46)^{f}$ & $<0.001$ & $27(22,35)$ \\
\hline $\mathrm{PHE}, \mu \mathrm{mol} / \mathrm{I}$ & $72(61,83)^{c}$ & $84(70,100)^{f}$ & $<0.001$ & $61(48,74)$ \\
\hline THR, $\mu \mathrm{mol} / \mathrm{I}$ & $126(101,154)$ & $142(118,173)^{f}$ & $<0.001$ & $119(92,150)$ \\
\hline TRP, $\mu \mathrm{mol} / \mathrm{l}$ & $56(47,67)^{\mathrm{b}}$ & $67(54,82)^{f}$ & $<0.001$ & $60(50,74)$ \\
\hline $\mathrm{VAL}, \mu \mathrm{mol} / \mathrm{I}$ & $214(182,247)^{c}$ & $304(241,376)^{f}$ & $<0.001$ & $172(143,208)$ \\
\hline \multicolumn{5}{|c|}{ Non-essential amino acids } \\
\hline ALA, $\mu \mathrm{mol} / \mathrm{I}$ & $440(346,526)$ & $420(349,517)$ & 0.304 & $430(355,495)$ \\
\hline ARG, $\mu \mathrm{mol} / \mathrm{I}$ & $115(97,137)$ & $110(91,128)$ & 0.038 & $113(91,129)$ \\
\hline ASN, $\mu \mathrm{mol} / \mathrm{I}$ & $54(45,64)$ & $58(47,68)^{\mathrm{e}}$ & 0.015 & $52(45,64)$ \\
\hline ASP, $\mu \mathrm{mol} / \mathrm{I}$ & $25(17,35)$ & $27(19,35)$ & 0.143 & $26(18,38)$ \\
\hline $\mathrm{GLN}, \mu \mathrm{mol} / \mathrm{l}$ & $605(542,683)^{c}$ & $556(490,613)^{f}$ & $<0.001$ & $664(573,748)$ \\
\hline $\mathrm{GLU}, \mu \mathrm{mol} / \mathrm{I}$ & $122(95,168)$ & $115(88,172)$ & 0.179 & $130(90,193)$ \\
\hline GLY, $\mu \mathrm{mol} / \mathrm{l}$ & $267(217,319)^{c}$ & $230(199,273)^{d}$ & $<0.001$ & $220(185,264)$ \\
\hline HIS, $\mu \mathrm{mol} / \mathrm{I}$ & $105(88,123)^{c}$ & $107(93,124)^{f}$ & 0.215 & $88(74,105)$ \\
\hline SER, $\mu \mathrm{mol} / \mathrm{I}$ & $161(138,194)^{\mathrm{c}}$ & $159(140,189)^{f}$ & 0.750 & $187(156,207)$ \\
\hline TYR, $\mu \mathrm{mol} / \mathrm{I}$ & $83(70,103)^{c}$ & $101(76,125)^{f}$ & $<0.001$ & $66(54,80)$ \\
\hline
\end{tabular}

Adapted from Socha et al. [71]. Values are expressed as median (IQR, 25th, 75th quartile).

${ }^{a} p<0.05$, LP vs. BF; ${ }^{b} p<0.01, L P$ vs. BF; ${ }^{c} p<0.001, L P$ vs. BF; ${ }^{d} p<0.05, H P$ vs. BF;

e $p<0.01$, HP vs. BF; ${ }^{f} p<0.001$, HP vs. BF.

the breastfed and the formula groups (table 3 ). Essential amino acids, especially branched-chain amino acids, were lower in the breastfed than in the LP group, whereas non-essential amino acids had about the same level.

Total IGF-I was found positively correlated with weight-for-length at 6 (fig. 5), 12, and 24 months, whereas C-peptide showed no association with weight-for-length.

\section{Conclusions}

Breastfeeding or formula feeding and dietary protein supply in infancy were found to markedly affect the metabolic and endocrine response of infants, and their growth. HP intakes increase the plasma levels of essential amino acids, especially branched-chain amino acids, serum concentrations of total and 
Table 3. Serum concentrations of free and total IGF-I IGF-BP2 and IGF-BP3, glucose and urea, and of urinary $\mathrm{C}$-peptide in infants on LP and HP and in BF infants

\begin{tabular}{lllll}
\hline Parameter & LP & HP & P (HP & BF \\
& & & vs. LP) & \\
\hline IGF-I free, ng/ml & $0.43(0.27,-0.77)^{\mathrm{a}}$ & $0.60(0.34,1.11)^{\mathrm{b}}$ & $<0.001$ & $0.31(0.21,0.48)$ \\
\hline IGF-I total, ng/ml & $34.7(17.7,57.5)^{\mathrm{a}}$ & $48.4(27.2,81.8)^{\mathrm{b}}$ & $<0.001$ & $14.1(5.1,33.2)$ \\
\hline IGF-BP2, ng/ml & $1,090(865,1,438)$ & $765(575,1,013)$ & $<0.001$ & $1,370(1,055,1,740)$ \\
\hline IGF-BP3, ng/ml & $2,908(2,449,3,440)$ & $2,969(2,538,3,483)$ & 0.248 & $2,454(1,984,2,794)$ \\
\hline C-peptide/ & $107.3(65.2,194.7)^{\mathrm{a}}$ & $140.6(80.0,203.8)^{\mathrm{b}}$ & 0.030 & $57.0(27.3,119.3)$ \\
creatinine ng/mg & & & & \\
\hline C-peptide, ng/ml & $19.5(9.4,34.6)^{\mathrm{a}}$ & $26.9(13.3,45.6)^{\mathrm{b}}$ & 0.002 & $9.3(3.5,20.1)$ \\
\hline Glucose, mg/dl & $85(77,93)$ & $83(77,89)^{\mathrm{b}}$ & 0.022 & $86(79,93)$ \\
\hline Urea, mg/dl & $18(14,21)^{\mathrm{a}}$ & $29(20,36)^{\mathrm{b}}$ & $<0.001$ & $11(8,16)$ \\
\hline
\end{tabular}

Adapted from Socha et al. [71]. Values are expressed as median (IQR, 25th, 75th quartile).

${ }^{a} p<0.001$, LP vs. BF; ${ }^{b} p<0.001, H P$ vs. BF.

free IGF-I, and urinary C-peptide levels which reflect increased insulin secretion, while the serum glucose level was lowered. Using infant formula with LP content results in a more similar - but not equal - metabolic and endocrine response as compared to breastfed infants, while it normalizes weight and BMI of formula-fed babies relative to healthy breastfed subjects during the first 2 years of life.

The observed marked effects of formula protein contents on total and free IGF-I agree with earlier observations of lower IGF-I levels in breastfed compared to formula-fed infants, and in some studies with varying protein intakes, as reviewed by Socha et al. [71]. The observed correlation of IGF-I levels with weight-for-length leads us to conclude that IGF-I is a key driver of weight gain during infancy, which clearly can be modulated to a biologically relevant extent by dietary composition. In addition to modulating growth, elevated IGF-I levels in infancy may also have further long-term effects. Formula feeding, HP intakes, and higher IGF-I levels in infancy have been associated with lower IGF-I levels in later life [72-75], whereas breastfeeding is associated with lower IGF-I in infancy but higher IGF-I in later childhood [72]. In healthy adults, a lower IGF-I concentration has been associated with an increased risk of both ischemic heart disease and diabetes [76] as well as with increased incidence of malignancies such as prostate and breast cancer [77]. Therefore, programming of the IGF-I axis through early nutrition in infancy may have a considerable impact on the later risk not only of obesity but also of other 


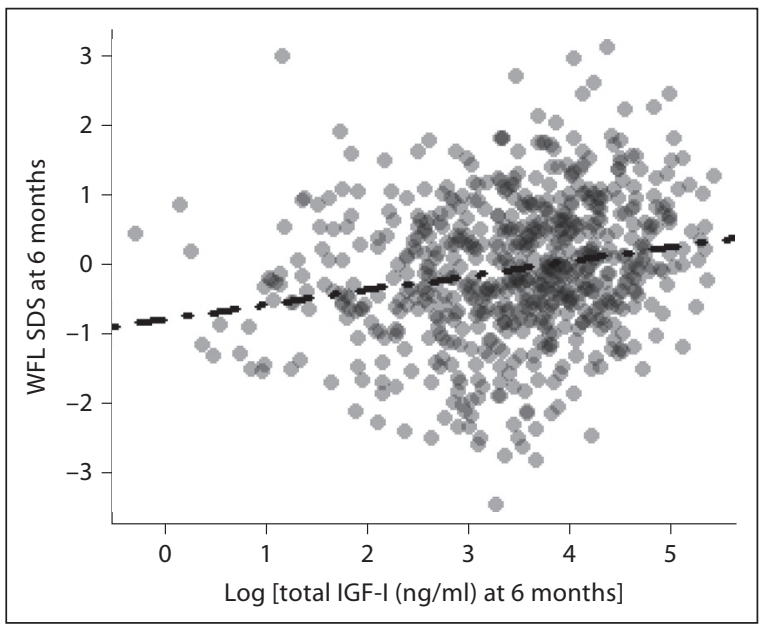

Fig. 5. At the age of 6 months, total IGF-I (log scale) is a significant predictor of weightfor-length (WFL) SDS in 513 infants participating in the European Childhood Obesity Trial (rho $=0.24, p<0.001)$. Drawn from data of Socha et al. [70].

adult diseases [72]. While lowering protein supply decreased IGF-I levels, these still remained far higher than the levels observed in breastfed babies. Thus, further exploration of the regulators of the IGF-I axis in early life is needed, including the investigation of the effects of IGF gene variants on IGF-I and its binding proteins, and their interaction with nutrition and growth.

Given that insulin plays a central role in metabolic regulation, IGF-I transcription and enhanced body fat deposition, the observed increased C-peptide levels by HP intake might also induce lasting effects on growth and health outcomes. Attenuation of the elevated insulin secretion though optimized early nutrition, such as LP intake in formula-fed babies, seems desirable. In addition to reducing protein supply with infant formula, the use of unmodified cows' milk as a drink during the first year of life, which provides very high protein intake, should be discouraged [78].

The available data should prompt enhanced efforts to actively promote, protect and support breastfeeding. For those infants that are not breastfed or not fully breastfed, we consider the use of infant formulas with reduced protein content but high protein quality preferable.

\section{Appendix}

The European Childhood Obesity Project Study Group

Philippe Goyens, Clotilde Carlier, Joana Hoyos (ULB, Bruxelles, Belgium), Françoise Martin, Annick Xhonneux, Jean-Paul Langhendries, Jean-Noel Van Hees (CHC St 
Vincent, Liège, Belgium), Ricardo Closa-Monasterolo, Joaquin Escribano, Veronica Luque, Georgina, Mendez, Natalia Ferre, Marta Zaragoza-Jordana (Universitat Rovira i Virgili, Tarragon, Spain), Marcello Giovannini, Enrica Riva, Carlo Agostoni, Silvia Scaglioni, Elvira Verduci, Fiammetta Vecchi, Alice Re Dionigi (University of Milan, Italy), Jerzy Socha, Anna Dobrzańska, Dariusz Gruszfeld, Piotr Socha, Anna Stolarczyk, Agnieszka Kowalik, Roman Janas, Ewa Pietraszek (Children's Memorial Health Institute, Warsaw, Poland), Emmanuel Perrin (Danone Research Centre for Specialized Nutrition, Schiphol, The Netherlands), Berthold Koletzko, Veit Grote, Martina Weber, Sonia Schiess, Jeannette Beyer, Michaela Fritsch, Uschi Handel, Ingrid Pawellek, Sabine Verwied-Jorky, Iris Hannibal, Hans Demmelmair, Gudrun Haile (Dr. von Hauner Childrens Hospital, University of Munich, Germany), Rüdiger von Kries (Institute for Social Paediatrics and Adolescent Medicine, University of Munich, Germany).

\section{Acknowledgements}

The studies reported herein have been carried out with partial financial support from the Commission of the European Communities, specific RTD Programme 'Quality of Life and Management of Living Resources', within the 5th Framework Programme, research grants No. QLRT-2001-00389 and QLK1-CT-2002-30582, the 6th Framework Programme, contract No. 007036, and the 7th Framework Programme, contract FP7289346-EARLY NUTRITION. This work does not necessarily reflect the views of the Commission and in no way anticipates the future policy in this area. Additional support from the European Research Council Advanced Grant No. 322605, the National Competence Network on Obesity, grant No. 01 GI 0825, German Ministry of Education and Research, Berlin, the Child Health Foundation, Munich, and the University of Munich Innovative Research Priority Project MC-Health (sub-project I) is gratefully acknowledged. Dr. Koletzko is the recipient of a Freedom to Discover Award of the Bristol-Myers-Squibb Foundation, New York, NY, USA. Funds to support the writing of the manuscript were provided by Nestlé Nutrition, Vevey, Switzerland.

\section{References}

1 Michaelsen KF: Child growth; in Koletzko B, Cooper P, Garza C, Makrides M, Uauy R, Wang W (eds): Pediatric Nutrition - A Practical Reference Guide. Basel, Karger, 2008.

2 Szajewska H, Makrides M: Is early nutrition related to short-term health and long-term outcome? Ann Nutr Metab 2011; 58(Suppl 1):38-48.

-3 Patel MS, Srinivasan M: Metabolic programming in the immediate postnatal life. Ann Nutr Metab 2011;58(Suppl 2):18-28.

4 Xiang L, He G: Caloric restriction and antiaging effects. Ann Nutr Metab 2011;58:42-48.
5 Karlberg J: A biologically-oriented mathematical model (ICP) for human growth. Acta Paediatr Scand Suppl 1989;350:70-94.

6 Hill DJ, Hogg J: Growth factors and the regulation of pre- and postnatal growth. Baillieres Clin Endocrinol Metab 1989;3:579-625.

7 Hogg J, Han VK, Clemmons DR, Hill DJ: Interactions of nutrients, insulin-like growth factors (IGFs) and IGF-binding proteins in the regulation of DNA synthesis by isolated fetal rat islets of Langerhans. J Endocrinol 1993;138:401-412. 
8 Ketelslegers JM, Maiter D, Maes M, et al: Nutritional regulation of insulin-like growth factor-I. Metabolism 1995;44(Suppl 4):50-57.

-9 Baumann G: Growth hormone binding protein 2001. J Pediatr Endocrinol Metab 2001;14:355-375.

10 Ong KK, Elmlinger M, Jones R, et al: Growth hormone binding protein levels in children are associated with birth weight, postnatal weight gain, and insulin secretion. Metabolism 2007;56:1412-1417.

-11 Newsholme P, Gaudel C, McClenaghan NH: Nutrient regulation of insulin secretion and beta-cell functional integrity. Adv Exp Med Biol 2010;654:91-114.

12 Muntoni S: Insulin resistance: pathophysiology and rationale for treatment. Ann Nutr Metab 2011;58:25-36.

13 de Oliveira CA, Latorraca MQ, de Mello MA, Carneiro EM: Mechanisms of insulin secretion in malnutrition: modulation by amino acids in rodent models. Amino Acids 2011;40:1027-1034.

14 Yang J, Chi Y, Burkhardt BR, et al: Leucine metabolism in regulation of insulin secretion from pancreatic beta cells. Nutr Rev 2010;68:270-279.

15 Polak P, Hall MN: mTOR and the control of whole body metabolism. Curr Opin Cell Biol 2009;21:209-218.

16 Polak P, Cybulski N, Feige JN, et al: Adiposespecific knockout of raptor results in lean mice with enhanced mitochondrial respiration. Cell Metab 2008;8:399-410.

$\checkmark 17$ Koletzko B, von Kries R, Monasterolo RC, et al: Infant feeding and later obesity risk. Adv Exp Med Biol 2009;646:15-29.

18 Hanley B, Dijane J, Fewtrell M, et al: Metabolic imprinting, programming and epigenetics - a review of present priorities and future opportunities. Br J Nutr 2010;104(Suppl 1):S1-S25.

19 Koletzko B, Decsi T, Molnar D, de la Hunty A (eds): Early Nutrition Programming and Health Outcomes in Later Life: Obesity and Beyond. New York, Springer, 2009.

20 Dörner G: Perinatal hormone levels and brain organization; in Stumpf WE, Grant LD (eds): Anatomical Neuroendocrinology. Basel, Karger, 1975, pp 245-252.

-21 Ruemmele FM: Early programming effects of nutrition - life-long consequences? Ann Nutr Metab 2011;58(Suppl 2):5-6.
22 Tounian P: Programming towards childhood obesity. Ann Nutr Metab 2011;58(Suppl 2): 30-41.

23 Koletzko B, Symonds ME, Olsen SF: Programming research: where are we and where do we go from here? Am J Clin Nutr 2011;94:2036S-2043S.

24 Koletzko B, von Kries R, Closa R, et al: Lower protein in infant formula is associated with lower weight up to age $2 \mathrm{y}$ : a randomized clinical trial. Am J Clin Nutr: 2009;89:1836-1845.

25 McCance RA, Widdowson EM: The determinants of growth and form. Proc R Soc Lond B Biol Sci 1974;185:1-17.

26 Lamb MM, Dabelea D, Yin X, et al: Earlylife predictors of higher body mass index in healthy children. Ann Nutr Metab 2010;56:16-22.

27 Koletzko B, von Kries R, Closa R, et al: Can infant feeding choices modulate later obesity risk? Am J Clin Nutr 2009;89:1502S-1508S.

28 Toschke AM, Grote V, Koletzko B, von Kries R: Identifying children at high risk for overweight at school entry by weight gain during the first 2 years. Arch Pediatr Adolesc Med 2004;158:449-452.

29 Baird J, Fisher D, Lucas P, et al: Being big or growing fast: systematic review of size and growth in infancy and later obesity. BMJ 2005;331:929.

30 Monteiro PO, Victora CG: Rapid growth in infancy and childhood and obesity in later life - a systematic review. Obes Rev 2005;6:143-154.

-31 Ong KK, Loos RJ: Rapid infancy weight gain and subsequent obesity: systematic reviews and hopeful suggestions. Acta Paediatr 2006;95:904-908.

-32 Druet C, Ong KK: Early childhood predictors of adult body composition. Best Pract Res Clin Endocrinol Metab 2008;22:489-502.

33 Adair LS: Child and adolescent obesity: epidemiology and developmental perspectives. Physiol Behav 2008;94:8-16.

34 Metcalfe NB, Monaghan P: Compensation for a bad start: grow now, pay later? Trends Ecol Evol 2001;16:254-260.

35 Koletzko B, Akerblom H, Dodds PF, Ashwell $\mathrm{M}$ (eds): Early nutrition and its later consequences: new opportunities. New York, Springer, 2005. 
36 Wells JC: The programming effects of early growth. Early Hum Dev 2007;83:743-748.

37 Bansal N, Ayoola OO, Gemmell I, et al: Effects of early growth on blood pressure of infants of British European and South Asian origin at one year of age: the Manchester children's growth and vascular health study. J Hypertens 2008;26:412-418.

38 Stettler N: Nature and strength of epidemiological evidence for origins of childhood and adulthood obesity in the first year of life. Int J Obes (Lond) 2007;31:1035-1043.

39 Gonzalez DA, Nazmi A, Victora CG: Growth from birth to adulthood and abdominal obesity in a Brazilian birth cohort. Int J Obes (Lond) 2010;34:195-202.

40 Horta BL, Victora CG, Lima RC, Post P: Weight gain in childhood and blood lipids in adolescence. Acta Paediatr 2009;98: 1024-1028.

41 Dunger DB, Salgin B, Ong KK: Session 7: early nutrition and later health early developmental pathways of obesity and diabetes risk. Proc Nutr Soc 2007;66:451-457.

42 Flaherman V, Rutherford GW: A metaanalysis of the effect of high weight on asthma. Arch Dis Child 2006;91:334-339.

43 Paul IM, Camera L, Zeiger RS, et al: Relationship between infant weight gain and later asthma. Pediatr Allergy Immunol 2010;21(1 Pt 1):82-89.

44 Litonjua AA, Gold DR: Asthma and obesity: common early-life influences in the inception of disease. J Allergy Clin Immunol 2008;121:1075-1084, quiz 85-86.

45 Agency for Healthcare Research and Quality: Breastfeeding and maternal and infant health outcomes in developed countries. AHRQ Publication No 07-E007, 2007, p 524.

46 Dutch State Institute for Nutrition and Health, Van Rossum CMT, Büchner FL, Hoekstra J: Quantification of health effects of breastfeeding. Review of the literature and model situation. RIVM Report $350040001 / 2005$.

47 Rebhan B, Kohlhuber M, Schwegler U, et al: Breastfeeding duration and exclusivity associated with infants' health and growth: data from a prospective cohort study in Bavaria, Germany. Acta Paediatr 2009;98:974-980.

48 Victora CG, Morris SS, Barros FC, et al: Breast-feeding and growth in Brazilian infants. Am J Clin Nutr 1998;67:452-458.
49 Ong KK, Preece MA, Emmett PM, et al: Size at birth and early childhood growth in relation to maternal smoking, parity and infant breast-feeding: longitudinal birth cohort study and analysis. Pediatr Res 2002;52:863-867.

50 Dewey KG: Growth characteristics of breastfed compared to formula-fed infants. Biol Neonate 1998;74:94-105.

51 von Kries R, Koletzko B, Sauerwald T, et al: Breast feeding and obesity: cross sectional study. BMJ 1999;319:147-150.

52 Arenz S, Ruckerl R, Koletzko B, von Kries R: Breast-feeding and childhood obesity - a systematic review. Int J Obes Relat Metab Disord 2004;28:1247-1256.

53 Harder T, Bergmann R, Kallischnigg G, Plagemann A: Duration of breastfeeding and risk of overweight: a meta-analysis. Am J Epidemiol 2005;162:397-403.

54 Owen CG, Martin RM, Whincup PH, et al: Effect of infant feeding on the risk of obesity across the life course: a quantitative review of published evidence. Pediatrics 2005;115:1367-1377.

55 Kramer MS, Matush L, Vanilovich I, et al: A randomized breast-feeding promotion intervention did not reduce child obesity in Belarus. J Nutr 2009;139:417S-421S.

56 Beyerlein A, von Kries R: Breastfeeding and body composition in children: will there ever be conclusive empirical evidence for a protective effect against overweight? Am J Clin Nutr 2011, Epub ahead of print.

-57 Beyerlein A, Toschke AM, von Kries R: Breastfeeding and childhood obesity: shift of the entire BMI distribution or only the upper parts? Obesity (Silver Spring) 2008;16: 2730-2733.

58 Koletzko B: Marketing of dietetic products for infants and young children in Europe three decades after adoption of the International Code of Marketing of Breast Milk Substitutes. Ann Nutr Metab 2011;59:70-72.

59 Koletzko B, Hartmann W, Albring C, für die Deutsche Gesellschaft für Kinder- und Jugendmedizin, den Berufsverband der Kinder- und Jugendärzte, den Berufsverband der Frauenärzte, et al: Unakzeptable Werbemaßnahmen für Säuglingsnahrungen. Dtsch Arztebl 2011;108:A2268-A2269. 
60 Alexy U, Kersting M, Sichert-Hellert W, et al: Macronutrient intake of 3- to 36-month-old German infants and children: results of the DONALD Study. Dortmund Nutritional and Anthropometric Longitudinally Designed Study. Ann Nutr Metab 1999;43:14-22.

61 Heinig MJ, Nommsen LA, Peerson JM, et al: Energy and protein intakes of breast-fed and formula-fed infants during the first year of life and their association with growth velocity: the DARLING Study. Am J Clin Nutr 1993;58:152-161.

62 Koletzko B, Broekaert I, Demmelmair H, et al: Protein intake in the first year of life: a risk factor for later obesity? The E.U. Childhood Obesity Project. Adv Exp Med Biol 2005;569:69-79.

63 Baird J, Poole J, Robinson S, et al: Milk feeding and dietary patterns predict weight and fat gains in infancy. Paediatr Perinat Epidemiol 2008;22:575-586.

64 Parizkova J, Rolland-Cachera MF: High proteins early in life as a predisposition for later obesity and further health risks. Nutrition 1997;13:818-819.

65 Gunther AL, Remer T, Kroke A, Buyken AE: Early protein intake and later obesity risk: which protein sources at which time points throughout infancy and childhood are important for body mass index and body fat percentage at $7 \mathrm{y}$ of age? Am J Clin Nutr 2007;86:1765-1772.

66 Gunther AL, Buyken AE, Kroke A: Protein intake during the period of complementary feeding and early childhood and the association with body mass index and percentage body fat at $7 \mathrm{y}$ of age. Am J Clin Nutr 2007;85:1626-1633.

67 Gunther AL, Buyken AE, Kroke A: The influence of habitual protein intake in early childhood on BMI and age at adiposity rebound: results from the DONALD Study. Int J Obes (Lond) 2006;30:1072-1079.

68 Koletzko B, Brands B, Demmelmair H: The Early Nutrition Programming Project (EARNEST): 5 y of successful multidisciplinary collaborative research. Am J Clin Nutr 2011;94:1749S-1753S.

-69 Escribano J, Luque V, Ferre N, et al: Increased protein intake augments kidney volume and function in healthy infants. Kidney Int 2011;79:783-790.
70 Socha P, Grote V, Gruszfeld D, et al: Milk protein intake, the metabolic-endocrine response, and growth in infancy: data from a randomized clinical trial. Am J Clin Nutr 2011;94:1776S-1784S.

71 Socha P, Grote V, Gruszfeld D, et al: Milk protein intake, the metabolic-endocrine response, and growth in infancy: data from a randomized clinical trial. Am J Clin Nutr 2011;94(suppl 6):1776S-1784S.

72 Martin RM, Holly JM, Smith GD, et al: Could associations between breastfeeding and insulin-like growth factors underlie associations of breastfeeding with adult chronic disease? The Avon Longitudinal Study of Parents and Children. Clin Endocrinol (Oxf) 2005;62:728-737.

73 Ben-Shlomo Y, Holly J, McCarthy A, et al: Prenatal and postnatal milk supplementation and adult insulin-like growth factor I: longterm follow-up of a randomized controlled trial. Cancer Epidemiol Biomarkers Prev 2005;14:1336-1339.

74 Elias SG, Keinan-Boker L, Peeters PH, et al: Long term consequences of the 1944-1945 Dutch famine on the insulin-like growth factor axis. Int J Cancer 2004;108:628-630.

75 Larnkjaer A, Ingstrup HK, Schack-Nielsen L, et al: Early programming of the IGF-I axis: negative association between IGF-I in infancy and late adolescence in a 17-year longitudinal follow-up study of healthy subjects. Growth Horm IGF Res 2009;19:82-86.

76 Juul A, Scheike T, Davidsen M, et al: Low serum insulin-like growth factor I is associated with increased risk of ischemic heart disease: a population-based case-control study. Circulation 2002;106:939-944.

77 Pollak M: Insulin and insulin-like growth factor signalling in neoplasia. Nat Rev Cancer 2008;8:915-928.

78 Koletzko B, Brönstrup A, Cremer M, et al: Säuglingsernährung und Ernährung der stillenden Mutter. Handlungsempfehlungen - Ein Konsensuspapier im Auftrag des bundesweiten Netzwerk Junge Familie. Monatsschr Kinderheilkd 2010;158:679-689. 
